\title{
Development of an algorithm for calculating the number of regrindings for a shaver with the continuous spiral cutting edge
}

\author{
Aleksandr Golovko ${ }^{1, *}$ \\ ${ }^{1}$ Kazan Federal University, pr.Syuyumbike, d.10A, Naberezhnye Chelny, 423812 ,Russian \\ Federation
}

\begin{abstract}
There is a construction of tool of a worm type (shaver) at that a cutting wedge has the structurally performed clearance. In this case is possibility of the sequential processing of right and left side of profile of gear teeth of wheel different spiral cutting edges. It provides the increase of firmness of tool, diminishes auxiliary time, except the necessity of refixturing of wheel and promotes the productivity of process. For the effective use of shaver with spiral cutting edges it is important to define the exact meaning of amount of possible regrinds. An algorithm that allows to define the amount of possible regrinds of shaver is presented in the article.
\end{abstract}

One of variants of route of machining of points of gear-wheels, applied in an engineer, is the gear shaving, as to the semifinish operation before heat machining and gear honing [17].

The cutting wedge of the disk shaver when gear shaving is not fully geometrically satisfactory. The clearance on cutting edges are practically equal to zero. We would suggest this is the reason that the disk shavers machining of gear-wheels with large allowance (for example, after the preliminary rolling-up of gear teeth) is not possible. It is necessary to take into account high labour intensiveness of making of disk shavers, piece time on the gear grinding of that can be $5 . .6$ hours.

For finish machiningt of gear teeth of gear-wheels can be used multyteeth tool as a cup. These tool allow to realize so-called Power Skiving treatment (gear sharpening). However the special expensive equipment is required for realization of such type of machining.

The tools of a worm type with the helically-spiral cutting edges done on one lateral side of coils can be used for finish machining of gear teeth of gear-wheels $[8,9]$.

The lack of these tools is complication of construction and technology of making.

There is a construction of tool of a worm type (shaver). On every coil of shaver performed two continuous spiral cutting edges form at crossing of each of spiral sides of coil with the outward surface of tool [10] (Fig. 1).

The lack of this tool is that a cutting wedge does not have the structurally performed.

The construction of tool of a worm type (shaver) at that a cutting wedge has the structurally performed clearance is known [11].

\footnotetext{
*Corresponding author: a.n.gol@yandex.ru
} 


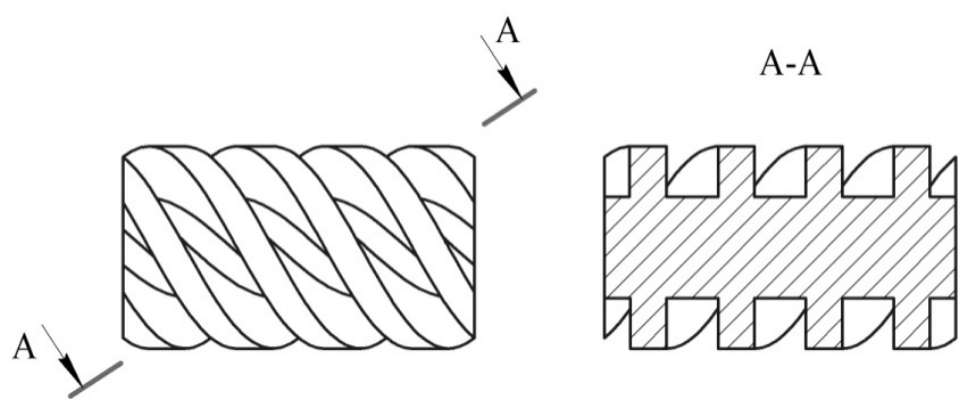

Fig. 1. Construction of the Tworm-type tool (shaver) with spiral cutting edges (Authors: N. Chemborisov, R. Khisamutdinov, V. Avdeev).

In this case is possibility of the sequential processing of right and left side of profile of gear teeth of wheel different spiral cutting edges. It provides the increase of firmness of tool, diminishes auxiliary time, except the necessity of refixturing of wheel and promotes the productivity of process.

Machining is produced at the concerted rotation of tool 1 and wheel 2 (Fig. 2).
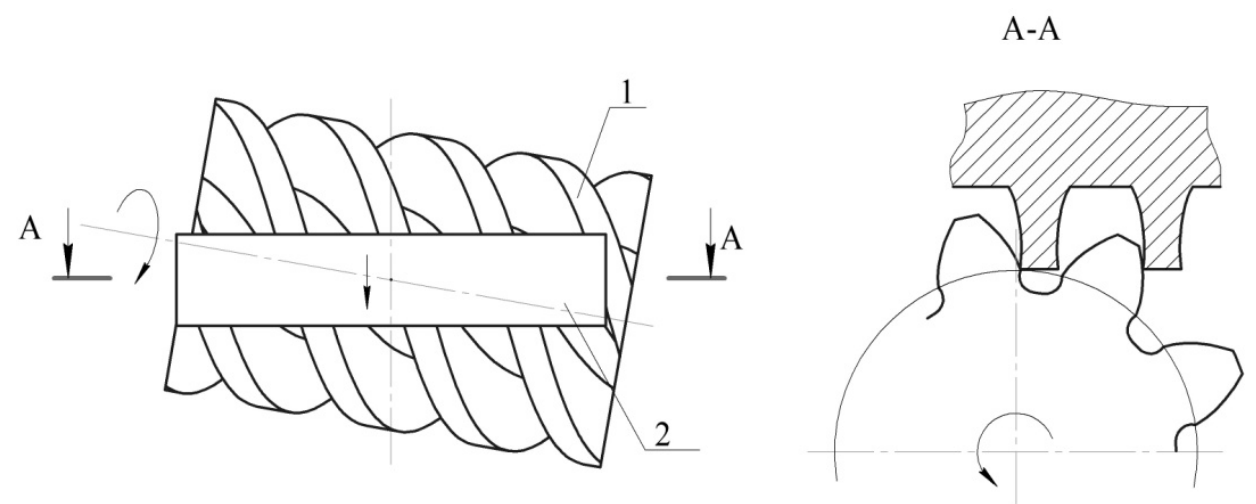

Fig. 2. Scheme of work of a worm-type tool with spiral cutting edges.

The worked out method allows to define the basic values of basic structural parameters of shaver with spiral cutting edges and parameters of his setting in relation to the purveyance of the processed gear-wheel [12-16].

The productive tests of shaver were conducted with spiral cutting edges with the diameter of circumference of ledges $d_{a 1}=77 \mathrm{~mm}$, by the number of stopping $z_{1}=7$ from high-speed steel of P6M5K5 on a gear-hobbing machine with numerical program control GearSpect SF 350/500 CNC.

The results of productive tests showed that the got precision considerations parameters of toothed crown of cog-wheel corresponded to the legitimate values.

For the effective use of shaver with spiral cutting edges it is important to define the exact meaning of amount of possible regrinds.

At a regrind the diameter of circumference of ledges $d_{a 1}$ will diminish on an outward cylindrical surface (to the front surface of instrument). Thus axial motion of spiral cutting edge $p_{z 1}$, is executed structurally at making, remains unchanging. At reduction $d_{a 1}$, and consequently and $r_{a 1}$ the corner of getting up of spiral cutting edge $\lambda_{1}$ and step of shaver will change only in a normal section $p_{n 1}$. 
The flow-chart of algorithm, allowing to define the amount of possible regrinds of shaver (Fig. 3), is worked out.

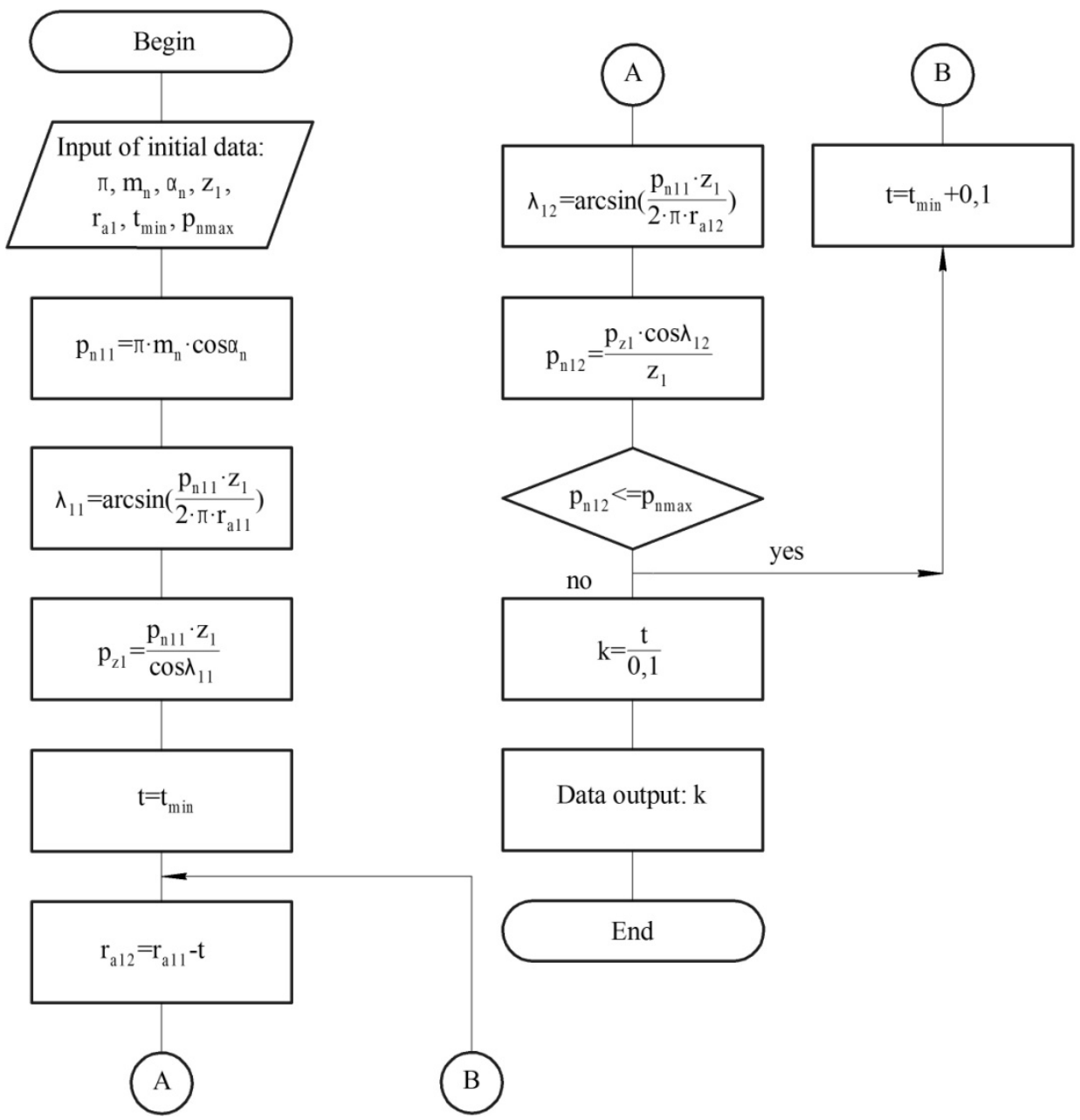

Fig. 3. Flow-chart of calculation of amount of possible regrinds of shaver with spiral cutting edges

Denotations used in the flow-chart of algorithm (Fig. 3) $: m_{n}$ - the module of cog-wheel in a normal section; $\alpha_{n}$ - a corner of profile of initial contour of cog-wheel in a normal section; $z_{1}$ - a number of stopping of shaver; $r_{a 11}$ - a radius of circumference of ledges of shaver; $t_{\min }$ - a minimum size of regrind; $p_{n \text { max }}$ - a maximally legitimate value of step of shaver in a normal section; $p_{n 11}$ - a step of shaver in a normal section to the regrind; $\lambda_{11}$ a corner of getting up of spiral cutting edge of shaver to the regrind; $p_{z 1}$ - axial motion of spiral cutting edge of shaver; $r_{a 12}$ - a radius of circumference of ledges of shaver after a regrind; $\lambda_{12}$ a corner of getting up of spiral cutting edge of shaver after a regrind; $p_{n 12}$ - a step of shaver in a normal section after a regrind; $k$ - an amount of possible regrinds.

It was set during a calculation, that the amount of possible regrinds on the front surface of tool is recommended no more than 5 . The size of every regrind is recommended an about 
$0,1 \mathrm{~mm}$, because this size must be hardly anymore allowance on machining, namely 0,06 MM.

The step of shaver in a normal section will make a $12,521 \mathrm{~mm}$ at reduction of diameter of circumference of ledges to $76 \mathrm{~mm}$. Difference of steps of shaver in a normal section to the regrinds and after 5-th regrind will make 0,026 MM. This value will be in admittance on the rejection of step $f_{p t}= \pm 0,028 \mathrm{~mm}$, that corresponds to the 8 th degree of exactness on the norms of smoothness of work.

\section{References}

1. A.A. Matalin, Manufacturing engineering (Lan, St. Petersburg, 2010)

2. M.F. Pashkevich, Manufacturing engineering. Course and degree design (Grevtsov's publishing house, Minsk, 2010)

3. V.L. Kulygin, Manufacturing engineering (BASTET, Moscow, 2011)

4. O.V. Taratynov, Manufacturing engineering. Design bases on the computer (FORUM, Moscow, 2011)

5. I.S. Ivanov, Manufacturing engineering (INFRA-M, Moscow, 2012)

6. R.M. Khusainov, S.Y. Yurasov, R.R. Kazargel'dinov, Preparations for production in unigraphics NX software, Russian Engineering Research, v. 37(4), pp. 363-366 (2017)

7. S.V. Kasjanov, A.G. Kondrashov, D.T. Safarov, Regulation of geometrical parameters deviations of automotive components parts through diagnostic measurements organization, Procedia Engineering, 206, pp. 1508-1514 (2017)

8. Inventor's certificate USSR, no. 1004030, 1983

9. Inventor's certificate USSR, no. 1106609, 1984

10. Patent RF, no. 103771, 2011

11. Patent RF, no. 2005013, 1993

12. A.N. Golovko, I.V. Golovko, Kinematic calculation of the error in gear shaving, Russian Engineering Research, v. 31(10), pp. 1034-1035 (2011)

13. A.N. Golovko, I.V. Golovko, Errors in the gear-tooth profile in shaving, Russian Engineering Research, v. 33(5), pp. 309-311 (2013)

14. A.N. Golovko, I.V. Golovko, Optimal design parameters of a shaving hob for compensation of the systematic error in the gear-tooth profile, Russian Engineering Research, v. 33(7), pp. 427-428 (2013)

15. A. Golovko, Determination of the profile of the worm-type tool, MATEC Web of Conferences, 129,01043 (2017)

16. A.N. Golovko, A.G. Kondrashov, S.Yu. Yurasov, Improved design of a worm type instrument for final machining of evolvent gear teeth, Procedia Engineering, 206, pp. 1333-1336 (2017) 